\title{
Pattern of amblyopia and fixation after keratoplasty
}

\author{
G. SINGH AND P. N. DAS \\ From the Department of Ophthalmology, Maulana Azad Medical College and \\ Irwin Hospital, New Delhi, India
}

SUMMARY Forty cases of clear corneal grafts in 2 groups of patients who developed corneal opacities either before or after 5 years of age were investigated for the pattern of amblyopia and fixation. A severe irreversible form of amblyopia with eccentric fixation was observed in cases of unilateral corneal opacity when the anomaly occurred before the age of 5 years and corneal grafting was delayed until the second or third decade of life. If the opacity was bilateral, although the onset was before the age of 5 years, the improvement in visual acuity after corneal grafting occurred in the relatively better eye with foveal fixation. Good visual results were seen after corneal grafting when the offending opacity occurred after the age of 5 years. Foveal fixation was also observed in most of these cases.

None of the patients who had a squint preoperatively lost their angle of strabismus. Four cases in group B, however, developed an alternating squint postoperatively.

After a successful corneal graft a patient may not regain vision owing to associated amblyopia. In India such a situation is encountered more frequently because corneal opacities due to keratomalacia, keratoconjunctivitis, and smallpox arise commonly in early childhood. Hence it is important to select cases for surgery to avoid disappointment and the waste of valuable donor material.

Data have been collected from the eye bank clinic at Irwin Hospital, where corneal grafting has been performed without consideration of the age of onset of corneal opacities. This provided an opportunity to study the density of amblyopia in patients who had clear media postoperatively.

\section{Materials and methods}

Forty cases of successful corneal grafts with clear optical media for at least 3 months were selected from the eye bank clinic at Irwin Hospital. Patients who had any pathological lesion in the media, retina, or visual pathways which might account for their low visual acuity were discarded. There were 33 cases of penetrating and 7 cases of lamellar corneal grafts.

Cases were divided into 2 groups according to

Address for reprints: Dr Gurbax Singh, Department of Ophthalmology, Maulana Azad Medical College and Irwin Hospital, New Delhi 110002, India the age of onset of corneal opacity. Cases with an onset before 5 years and after 5 years of age were labelled as groups A and B respectively. Each group comprised 20 cases (Tables 1 and 2).

Visual acuity was determined after refractive correction, utilising Snellen's whole-line optotypes. In cases of corneal opacity where visual acuity did not improve satisfactorily with glasses because of irregular astigmatism a contact lens was fitted to elicit the maximum visual improvement. Fixation pattern was determined with the help of the projectoscope after full mydriasis. The type of fixation and degree of eccentricity were graded according to the classification of Malik et al. (1969).

\section{Results}

All the cases in group A had an associated squint of varying degree whereas most of the cases in group B were orthophoric, although seven cases in this group of 19 had a small degree of squint (Fig. 1). The refractive state in both the groups showed astigmatism in almost all cases. The degree and type of refractive error in the two groups were comparable (Table 3).

Most of the cases selected for corneal grafting in both groups had very poor visual acuity, ranging from accurate projection of light to counting fingers. Postoperative visual gain in individual cases of group A and group B is shown in Fig. 2 
Table 1 Corneal opacity cases-onset before 5 years of age

\begin{tabular}{|c|c|c|c|c|c|c|c|}
\hline $\begin{array}{l}\text { Sl. } \\
\text { No. } \\
1\end{array}$ & $\begin{array}{l}\text { Patient's } \\
\text { age } \\
\text { (years) } \\
2\end{array}$ & $\begin{array}{l}\text { Corneal } \\
\text { onset } \\
\text { age in years } \\
3\end{array}$ & $\begin{array}{l}\text { Opacity, } \\
\text { duration } \\
\text { (years) } \\
4\end{array}$ & $\begin{array}{l}\text { Associated } \\
\text { squint } \\
5\end{array}$ & $\begin{array}{l}\text { Pre-op. } \\
\text { vision } \\
6\end{array}$ & $\begin{array}{l}\text { Post-op. } \\
\text { vision with } \\
\text { correction } \\
7\end{array}$ & $\begin{array}{l}\text { Fixation } \\
8\end{array}$ \\
\hline 1 & $8 \frac{1}{2}$ & 5 & $1 \frac{1}{2}$ & RCS & $\begin{array}{ll}\text { RE } & \text { CF } 3 M \\
\text { LE } & 6 / 6\end{array}$ & RE $6 / 18$ & $\begin{array}{ll}\text { RE Parafoveal } \\
\text { LE Foveal }\end{array}$ \\
\hline 2 & 12 & $\frac{1}{2}$ & 11 & $\begin{array}{l}\text { LDS } \\
\text { Nystagmus }\end{array}$ & $\begin{array}{l}\text { RE } 6 / 6 \\
\text { LE CF } 1^{\prime}\end{array}$ & LE CF $1^{\prime}$ & $\begin{array}{ll}\text { RE } & \text { Foveal } \\
\text { LE } & \text { Non-fix }\end{array}$ \\
\hline 4 & 8 & 1 & 6 & LCS & $\begin{array}{l}\text { RE } 6 / 6 \\
\text { LE CF 1, }\end{array}$ & LE CF 1' & $\begin{array}{ll}\text { RE } & \text { Foveal } \\
\text { LE } & \text { Non-fix. }\end{array}$ \\
\hline 5 & 16 & $\frac{1}{2}$ & 15 & RDS & $\begin{array}{ll}\text { RE } & \text { PR } \\
\text { LE } & 6 / 12\end{array}$ & RE HM 6" & $\begin{array}{l}\text { RE Paracaecal } \\
\text { LE Foveal }\end{array}$ \\
\hline 6 & 16 & 3 & 10 & RCS & $\begin{array}{l}\text { RE CF 2' } \\
\text { LE } 6 / 18\end{array}$ & RE CF 1' & $\begin{array}{l}\text { RE Paracaecal } \\
\text { LE Foveal }\end{array}$ \\
\hline 7 & 19 & 3 & 16 & RDS & $\begin{array}{l}\text { RE CF } \frac{1}{2} M \\
\text { LE } 6 / 6\end{array}$ & RE CF $\frac{1}{2} M$ & $\begin{array}{l}\text { RE Divergent } \\
\text { LE Foveal }\end{array}$ \\
\hline 9 & 32 & 2 & 30 & RDS & $\begin{array}{l}\text { RE CF 1M } \\
\text { LE: CF 1' }\end{array}$ & LE: $6 / 18$ & $\begin{array}{l}\text { RE: Not seen } \\
\text { LE: Foveal }\end{array}$ \\
\hline 10 & 25 & 3 & 20 & RCS & $\begin{array}{l}\text { RE: PR } \\
\text { LE: } 6 / 24 P\end{array}$ & LE: $6 / 18$ & $\begin{array}{l}\text { RE: Not seen } \\
\text { LE: Foveal }\end{array}$ \\
\hline 11 & 20 & 3 & 17 & $\mathrm{RCS}$ & $\begin{array}{l}\text { RE: CF } \frac{1}{2} M \\
\text { LE: } 6 / 6\end{array}$ & RE: CF $1 M$ & $\begin{array}{l}\text { RE: Paracaecal } \\
\text { LE: Foveal }\end{array}$ \\
\hline 12 & 22 & 2 & 16 & $\begin{array}{l}\text { RDS } \\
\text { Nystagmus }\end{array}$ & $\begin{array}{l}\text { RE: PR } \\
\text { LE } 6 / 6\end{array}$ & RE: CF 6" & $\begin{array}{l}\text { RE: Paracaecal } \\
\text { LE Foveal }\end{array}$ \\
\hline 13 & 22 & 1 & 21 & $\begin{array}{l}\text { RDS } \\
\text { Nystagmus }\end{array}$ & $\begin{array}{l}\text { RE: PR } \\
\text { LE: } 6 / 9\end{array}$ & RE: CF 6" & $\begin{array}{l}\text { RE: Non-fix. } \\
\text { LE: Foveal }\end{array}$ \\
\hline 14 & 24 & 1 & 18 & LDS & $\begin{array}{l}\text { RE: } 6 / 9 \\
\text { LE: CF } \frac{1}{2} M\end{array}$ & LE: CF $\frac{1}{2} \mathbf{M}$ & $\begin{array}{l}\text { RE: Foveal } \\
\text { LE: Paracaecal }\end{array}$ \\
\hline 15 & 18 & 3 & $14 \frac{1}{2}$ & RCS & $\begin{array}{l}\text { RE: CF } \frac{1}{2} M \\
\text { LE: } 6 / 12\end{array}$ & RE: CF & $\begin{array}{l}\text { RE: Paracaecal } \\
\text { LE: Foveal }\end{array}$ \\
\hline 16 & 22 & $\frac{1}{2}$ & 21 & RDS & $\begin{array}{l}\text { RE: CF } 1 M \\
\text { LE: } 6 / 6\end{array}$ & RE: CF 1M & $\begin{array}{l}\text { RE: Paracaecal } \\
\text { LE: Foveal }\end{array}$ \\
\hline 17 & 40 & 3 & 37 & RDS & $\begin{array}{l}\text { RE: HM } \\
\text { LE: } 6 / 12\end{array}$ & RE: CF 6" & $\begin{array}{l}\text { RE: Paracaecal } \\
\text { LE: Foveal }\end{array}$ \\
\hline 19 & 24 & 3 & $20 \frac{1}{2}$ & LDS & $\begin{array}{l}\text { RE: } 6 / 12 \\
\text { LE: CF 6" }\end{array}$ & LE: CF $\frac{1}{2} \mathbf{M}$ & $\begin{array}{l}\text { RE: Foveal } \\
\text { LE: Paracaecal }\end{array}$ \\
\hline 20 & 12 & 5 & 7 & $\mathrm{RCS}$ & $\begin{array}{l}\text { RE: CF 1' } \\
\text { LE: } 6 / 6\end{array}$ & RE: CF 1' & $\begin{array}{l}\text { RE: Paracaecal } \\
\text { LE: Foveal }\end{array}$ \\
\hline
\end{tabular}

Average age of onset $2 \cdot 2$ years. Average duration of corneal opacity $17 \cdot 4$ years.

and Fig. 3 respectively. In group A 16 cases $(80 \%)$ did not show any visual gain postoperatively. Four cases $(20 \%)$ showed slight to moderate improvement. Of these 4 cases, in 3 the operated eye was the only eye; the other eye had corneal opacities (Cases 8, 9 and 10, Table 1). In one case (Case 1) visual acuity improved from $3 / 60$ to $6 / 18$ postoperatively. The corneal opacity in this case developed at the age of 5 years and was operated upon $1 \frac{1}{2}$ years later. In group B 19 cases $(95 \%)$ had visual improvement after corneal grafting; in only 1 case (Case 1, Table 2) did visual acuity not improve. This patient was a 31-year-old male in whom a corneal leucoma developed in the right eye at the age of 17 after injury with a hockey ball. Corneal grafting was done 12 years later, and remained clear for 2 years. The patient had a divergent squint and divergent type of fixation in this eye.
In group A 11 cases in whom no visual gain was observed postoperatively had eccentric fixation, mostly centrocaecal or paracaecal in type; 6 cases had a divergent and 5 cases a convergent squint. Only 1 case had a divergent type of fixation with associated divergent type of squint. Four patients in this group who had associated divergent squint and nystagmus failed to show any particular retinal point of fixation. Nystagmus persisted after surgery. However, they had very widely eccentric areas of fixation. Case 1 (Table 1) had a parafoveal type of fixation and had shown a visual gain from $3 / 60$ to $6 / 18$ postoperatively. All the 3 cases of bilateral corneal opacity mentioned earlier had central fixation in the grafted eye.

In group B 18 cases $(90 \%)$ had central fixation and 2 cases $(10 \%)$ had eccentric fixation. The fixation pattern in the grafted eye in the 2 groups is shown in Fig. 4. 
Table 2 Corneal opacity cases-onset after 5 years of age

\begin{tabular}{|c|c|c|c|c|c|c|c|}
\hline $\begin{array}{l}\text { Sl. } \\
\text { No. } \\
1\end{array}$ & $\begin{array}{l}\text { Patient's } \\
\text { age } \\
\text { (years) } \\
2\end{array}$ & $\begin{array}{l}\text { Corneal } \\
\text { onset, } \\
\text { age in years } \\
3\end{array}$ & $\begin{array}{l}\text { Opacity } \\
\text { duration } \\
\text { (years) } \\
4\end{array}$ & $\begin{array}{l}\text { Associated } \\
\text { squint } \\
5\end{array}$ & $\begin{array}{l}\text { Pre-op. } \\
\text { vision } \\
6\end{array}$ & $\begin{array}{l}\text { Post-op. } \\
\text { vision with } \\
\text { correction } \\
7\end{array}$ & $\begin{array}{l}\text { Fixation } \\
8\end{array}$ \\
\hline 1 & 31 & 17 & 13 & RDS & $\begin{array}{l}\text { RE: CF 1M } \\
\text { LE: } 6 / 6\end{array}$ & RE: $2 / 60$ & $\begin{array}{l}\text { RE: Divergent } \\
\text { LE: Foveal }\end{array}$ \\
\hline 2 & 34 & 12 & 22 & RDS & $\begin{array}{l}\text { RE: CF 2' } \\
\text { LE: } 6 / 6\end{array}$ & RE: $6 / 18$ & $\begin{array}{l}\text { RE: Foveal } \\
\text { LE: Foveal }\end{array}$ \\
\hline 3 & 25 & 13 & 12 & Ortho-RCS & $\begin{array}{l}\text { RE: } 5 / 60 \\
\text { LE: } 6 / 12\end{array}$ & RE: $6 / 12$ & $\begin{array}{l}\text { RE: Foveal } \\
\text { LE: Foveal }\end{array}$ \\
\hline 4 & 46 & 21 & 19 & LDS & $\begin{array}{l}\text { RE: } 6 / 36 \\
\text { LE: } 6 / 60\end{array}$ & LE: $6 / 12$ & $\begin{array}{l}\text { RE: Not seen } \\
\text { LE: Foveal }\end{array}$ \\
\hline 5 & 20 & 13 & 7 & Ortho. & $\begin{array}{l}\text { RE: } 6 / 6 \\
\text { LE: CF 6" }\end{array}$ & LE: $6 / 6 \mathrm{P}$ & $\begin{array}{l}\text { RE: Foveal } \\
\text { LE: Foveal }\end{array}$ \\
\hline 6 & 25 & 20 & 5 & Ortho. & $\begin{array}{l}\text { RE: CF 1M } \\
\text { LE: } 6 / 6 \mathrm{P}\end{array}$ & RE: 6/9P & $\begin{array}{l}\text { RE: Foveal } \\
\text { LE: Foveal }\end{array}$ \\
\hline 7 & 16 & 7 & 4 & RDS & $\begin{array}{l}\text { RE: CF 1M } \\
\text { LE: } 6 / 6\end{array}$ & RE: $6 / 18 P$ & $\begin{array}{l}\text { RE: Parafoveal } \\
\text { LE: Foveal }\end{array}$ \\
\hline 8 & 18 & 11 & 4 & Ortho & $\begin{array}{l}\text { RE: } 6 / 60 \\
\text { LE: } 6 / 60\end{array}$ & RE: $6 / 12$ & $\begin{array}{l}\text { RE: Foveal } \\
\text { LE: Foveal }\end{array}$ \\
\hline 9 & 32 & 25 & 4 & Ortho. & $\begin{array}{l}\text { RE: } 6 / 60 \\
\text { LE: } P R\end{array}$ & RE: $6 / 12$ & $\begin{array}{l}\text { RE: Foveal } \\
\text { LE: Not seen }\end{array}$ \\
\hline 10 & 35 & 27 & 3 & Ortho. & $\begin{array}{l}\text { RE: } 6 / 9 \\
\text { LE: CF Im }\end{array}$ & LE: $6 / 9$ & $\begin{array}{l}\text { RE: Foveal } \\
\text { LE: Foveal }\end{array}$ \\
\hline 11 & 23 & 19 & $2 \frac{1}{2}$ & Ortho. & $\begin{array}{l}\text { RE: } 6 / 6 \mathrm{P} \\
\text { LE: } 6 / 60\end{array}$ & LE: $6 / 12$ & $\begin{array}{l}\text { RE: Foveal } \\
\text { LE: Foveal }\end{array}$ \\
\hline 12 & 20 & 14 & $1 \frac{1}{2}$ & Ortho. & $\begin{array}{l}\text { RE: } 6 / 6 \\
\text { LE: CF } 1 M\end{array}$ & LE: $6 / 9$ & $\begin{array}{l}\text { RE: Foveal } \\
\text { LE: Foveal }\end{array}$ \\
\hline 13 & 35 & 32 & $1 \frac{1}{2}$ & Ortho. & $\begin{array}{l}\text { RE: } 6 / 60 \\
\text { LE: CF } 6^{\prime \prime}\end{array}$ & LE: $6 / 12$ & $\begin{array}{l}\text { RE: Foveal } \\
\text { LE: Foveal }\end{array}$ \\
\hline 14 & 17 & 10 & 1 & Ortho. & $\begin{array}{l}\text { RE: } 6 / 36 \\
\text { LE: } 6 / 12 P\end{array}$ & RE: $6 / 18$ & $\begin{array}{l}\text { RE: Foveal } \\
\text { LE: Foveal }\end{array}$ \\
\hline 15 & 19 & 18 & 1 & RDS to ADS & $\begin{array}{l}\text { RE: } 6 / 60 \\
\text { LE: } 6 / 6\end{array}$ & RE: $6 / 12$ & $\begin{array}{l}\text { RE: Foveal } \\
\text { LE: Foveal }\end{array}$ \\
\hline 16 & 40 & 39 & 1 & LDS to ADS & $\begin{array}{l}\text { RE: } 6 / 9 \\
\text { LE: CF } 1 M\end{array}$ & LE: $6 / 9$ & $\begin{array}{l}\text { RE: Foveal } \\
\text { LE: Foveal }\end{array}$ \\
\hline 17 & 28 & 27 & 1 & Ortho. & $\begin{array}{l}\text { RE: } 6 / 6 \\
\text { LE: CF } 6^{\prime \prime}\end{array}$ & LE: 6/9P & $\begin{array}{l}\text { RE: Foveal } \\
\text { LE: Foveal }\end{array}$ \\
\hline 18 & 16 & 15 & 1 & Ortho. & $\begin{array}{l}\text { RE: CF 2' } \\
\text { LE: } 6 / 6\end{array}$ & RE: $6 / 9$ & $\begin{array}{l}\text { RE: Foveal } \\
\text { LE: Foveal }\end{array}$ \\
\hline 19 & 20 & 19 & 1 & Ortho. & $\begin{array}{l}\text { RE: } 6 / 6 \\
\text { LE: CF } 1 M\end{array}$ & LE: $6 / 6 \mathrm{P}$ & $\begin{array}{l}\text { RE: Foveal } \\
\text { LE: Foveal }\end{array}$ \\
\hline 20 & 14 & 13 & 1 & - & $\begin{array}{l}\text { RE: Enucleated } \\
\text { LE: } 5 / 60\end{array}$ & LE: $6 / 9 \mathrm{P}$ & $\begin{array}{l}\text { RE:- } \\
\text { LE: Foveal }\end{array}$ \\
\hline
\end{tabular}

Average age of onset $19 \cdot 1$ years. Average duration of corneal opacity $5 \cdot 3$ years.

Table 3 Showing the type of refractive error in the grafted eye

\begin{tabular}{lllll}
\hline & $\begin{array}{l}\text { Hypermetropic } \\
\text { astigmatism }\end{array}$ & $\begin{array}{l}\text { Myopic } \\
\text { astigmatism }\end{array}$ & $\begin{array}{l}\text { Mixed } \\
\text { astigmatism }\end{array}$ & $\begin{array}{l}\text { Irregular } \\
\text { astigmatism }\end{array}$ \\
\hline Group A & 6 & 6 & 4 & 4 \\
Group B & 8 & 8 & 4 & - \\
\hline
\end{tabular}

\section{Discussion}

It is known that the structure of the peripheral organ of vision is almost complete at birth but that vision develops gradually. Its development depends on adequate stimulation of the retina by light and objects during early infancy and childhood. When such stimulation is denied to the eyes by opacity in the ocular media early in life a condition of irreversible loss of visual acuity develops which is termed stimulus-deprivation amblyopia (Von Noorden, 1967). In experiment studies by Chow et al. (1957), Wiesel and Hubel (1963a, b, c, 1965a, b), Von Noorden et al. (1970), and Goswamy and Agarwal (1971) severe irreversible amblyopia was induced in animals when their eyes were occluded (either by suturing the lids or by plastic occluder or by producing corneal scarification) during the first few months of life. No comparable visual defect was observed when these experiments were repeated in adult animals. Though such data cannot be transferred to man without reservation the results of occlusion appear to be similar to clinical amblyopia.

The present study shows that, when a corneal opacity is unilateral and arises before 5 years of age and corneal grafting is delayed until adulthood, a severe amblyopia develops. If, however, the corneal opacities are bilateral, the amblyopia is not very dense at least in one eye, and good visual 


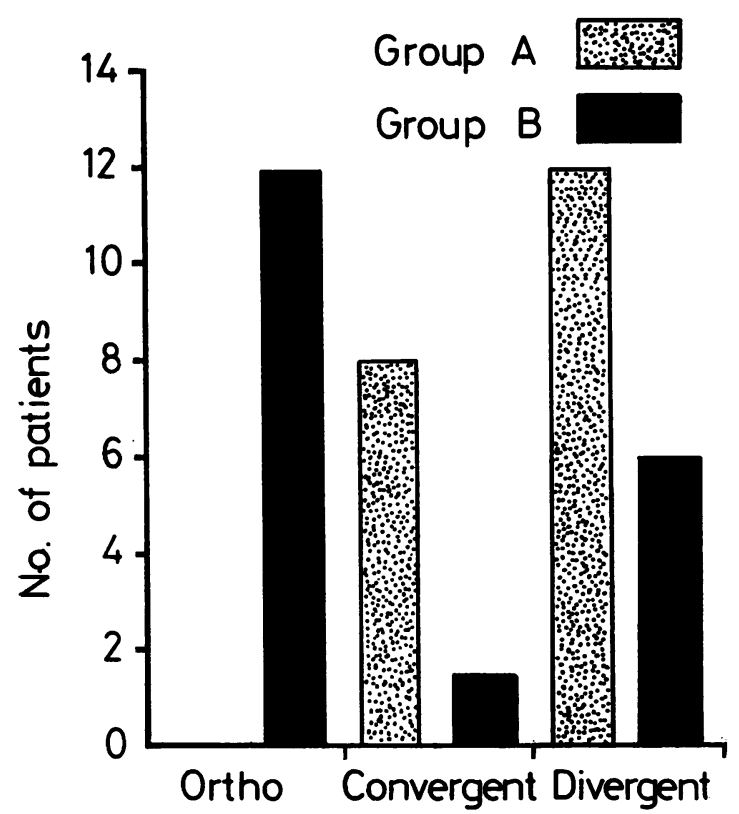

Fig. 1 Nature of associated squint

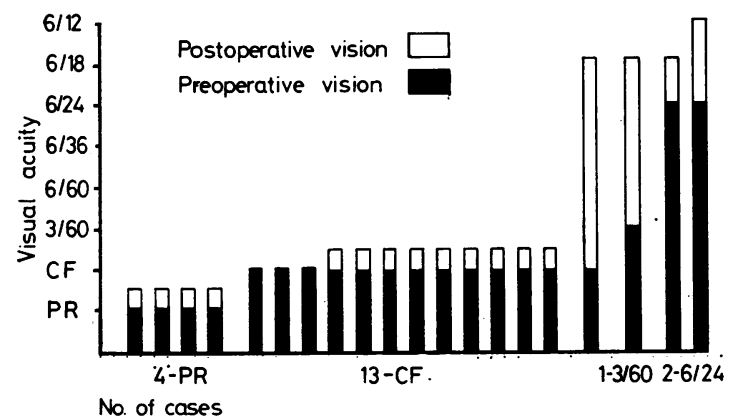

Fig. 2 Group A: Postoperative visual gain

improvement takes place (case 9, Table 1). Von Noorden and Maumenee (1968) recorded 3 similar cases. They did not find visual improvement in cases of unilateral corneal opacity, but some visual improvement was seen in two cases of bilateral corneal opacity. Picetti and Fine (1966) also observed good visual gain in 2 cases of bilateral congenital corneal dystrophy even though they were operated on at 7 years of age.

In the present series all the cases of unilateral corneal opacity before 5 years of age developed eccentric fixation, but if the corneal opacity was bilateral then in the relatively better eye foveal fixation was preserved and visual gain obtained (Cases 8, 9 and 10, Table 1).

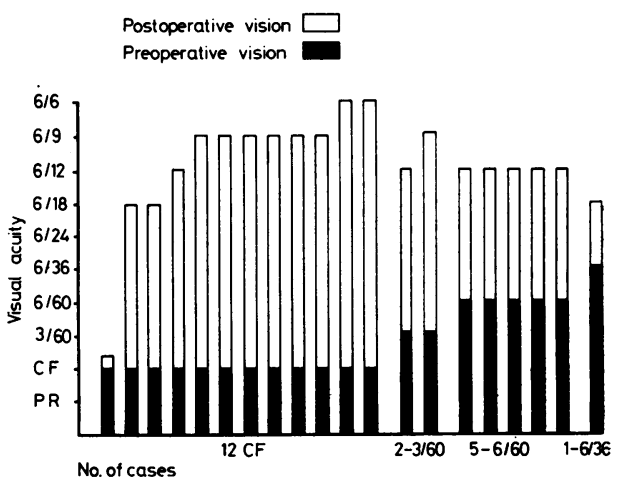

Fig. 3 Group B: Postoperative visual gain

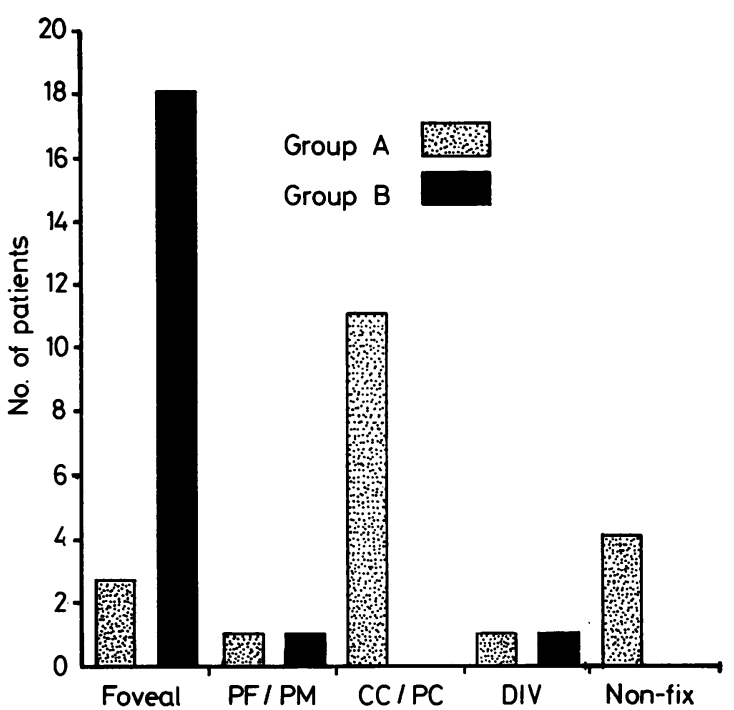

Fig. 4 Fixation pattern (groups $A$ and $B$ )

The present series also clearly indicates that when corneal opacity develops after 7 years of age it has no significant influence on the development of amblyopia and fixation pattern irrespective of the duration of the opacity before surgery. However, if the corneal opacity is unilateral and develops around the border line age of 5 and 7 years (Case 1 , Table 1 and case 7, Table 2) there is less improvement in visual acuity with the parafoveal type of eccentric fixation.

\section{References}

Chow, K. L., Riesen, A. H., and Newell, F. W. (1957). Journal of Comparative Neurology, 107, 27.

Goswamy, S., and Agarwal, L. P. (1971). Indian Journal of Medical Research, 59, 957. 
Malik, S. R. K., Gupta, A. K., and Chowdhury, S. (1969). British Journal of Ophthalmology, 53, 188.

Picetti, B., and Fine, M. (1966). American Journal of Ophthalmology, 61, 782.

Von Noorden, G. K. (1967). American Journal of Ophthalmology, 63, 238.

Von Noorden, G. K., and Maumenee, A. E. (1968). American Journal of Ophthalmology, 65, 220.

Von Noorden, G. K., Dowling, J. E., and Ferguson, D. C. (1970). Archives of Ophthalmology, 84, 206.
Wiesel, T. N., and Hubel, D. H. (1963a). Journal of Neurophysiology, 26, 979.

Wiesel, T. N., and Hubel, D. H. (1963b). Journal of Neurophysiology, 26, 994.

Wiesel, T. N., and Hubel, D. H. (1963c). Journal of Neurophysiology, 26, 1003.

Wiesel, T. N., and Hubel, D. H. (1965a). Journal of Neurophysiology, 28, 1029.

Wiesel, T. N., and Hubel, D. H. (1965b). Journal of Neurophysiology, 28, 1060. 